\title{
Surgical management and outcome of intramedullary spinal cord tumour
}

\author{
Mohammad Fathy * (D), Mohamed Keshk and Ahmed El Sherif
}

\begin{abstract}
Objective: Our aim is to assess the surgical management of intramedullary spinal cord tumours (IMSCTs) and evaluate factors associated with surgical outcomes in our hospitals.

Patient and methods: Between June 2013 and June 2016, a retrospective study was conducted on 16 consecutive cases of IMSCTs. All patients provided their signed consent, and MRI was performed. The patients were surgically treated and were evaluated pre- and post-operatively by the modified McCormick scale (MMS). Appropriate statistical analysis was conducted.

Results: The mean patient age was 50.4 years, and the median follow-up was 15 months. The most common histological origin was ependymoma $(n=9,56.25 \%)$. A cervical tumour was detected in eight patients, and a dorsal tumour was detected in seven. Post-operatively, the score was clinically but not statistically improved in seven cervical $(87.5 \%)$ and four dorsal $(57.1 \%)$ tumours $(p=0.334)$. Ten patients underwent total resection. Post-operative MMS scores showed improvement in all cases of total resection $(n=10,100 \%)$. This improvement was clinically and statistically significant on last follow-up $(p=0.008)$. Fewer than four segments were involved in 9 cases, and more than four segments were involved in 7 cases. Post-operatively, all 9 patients (100\%) with fewer than four involved segments improved, while only three patients (42.9\%) with more than 4 involved segments improved ( $p=0.019)$. Low-grade tumours such as ependymomas were correlated with good surgical outcomes, while high-grade tumours such as astrocytomas were correlated with poor surgical outcomes $(p=0.022)$.
\end{abstract}

Conclusions: Total tumour resection coupled with good preoperative clinical condition for tumours localised in the cervical or conus region predicts good neurological outcomes. Tumour localisation in the dorsal region with multisegmental extension and high-grade tumour pathology predicts poor neurological outcomes.

Keywords: Intramedullary, Spinal cord tumour, Modified McCormick scale, Spinal cord, Outcome

\section{Introduction}

Surgery for intramedullary spinal cord tumours (IMSCTs), due to their relative infrequency, unknown natural history, and surgical difficulty, remains one of the major challenges for neurosurgeons [1]. IMSCTs account for $2-4 \%$ of all central nervous system neoplasms and approximately $20-25 \%$ of all spinal tumours [2]. The most common intramedullary neoplasm is spinal ependymoma, followed by glioma and other lesions [3]. Surgical outcomes of patients with IMSCTs have been improved due to advances in diagnostic imaging tools, microsurgical techniques, surgical equipment, and neurophysiologic monitoring.

\footnotetext{
* Correspondence: m_f_neuro@hotmail.com

Neurosurgery Departments, Al-Azhar University, Cairo, Egypt
}

The purpose of our study was to review the recent management of IMSCTs at our hospitals. In addition, we analysed the prognostic factors affecting neurological outcome after surgical resection of IMSCTs.

\section{Materials and methods}

This is a retrospective study. Between June 2013 and June 2016, 16 patients with an IMSCT were admitted and underwent surgical treatment at Al-Azhar University hospitals, Cairo, Egypt, and Mohammad Dossary hospital, Al-Khobar City, Eastern Province, Kingdom of Saudi Arabia. The patients were identified by the medical records department of the hospitals. Ethical approval was obtained from each patient and was reviewed in the medical records department. Patient charts and surgical 
and histological reports were analysed. A standardised telephone interview was performed in patients with no follow-up charts. As shown in Table 1, there were 12 males (75\%) and 4 females (25\%). The mean patient age was 50.4 years, ranging from 18 to 70 years. The post-operative follow-up period ranged from 4 to 36 months (mean 15 months). Basic demographic data, clinical presentation, and radiologic exams were retrospectively reviewed for each patient. Patients' neurological status before surgery, immediately after surgery and at last follow-up, was graded using the modified McCormick scale (MMS) (Table 2) [4].

Clinical presentation was divided into motor weakness, pain, sensory change, and sphincter problems. The histological origins of IMSCTs were classified into neuroepithelial and non-neuroepithelial tumours. Neuroepithelial tumours were classified as low-grade tumours (grades I, II) and high-grade tumours (grades III, IV, V) by the World Health Organization (WHO) classification. Tumour removal was classified as macroscopic gross total resection (TR) (100\%), subtotal resection (STR) (> $90 \%$ ), or open biopsy. TR was defined as complete removal of the tumour proven intraoperative by microscopy and post-operatively by MRI. All patients underwent MRI pre- and post-operatively. Tumour localizations were divided into cervical, thoracic, and conus medullaris. The level of tumour extension was classified into fewer than four involved segments and four or more segments.

\section{Surgical considerations}

All patients underwent the procedure in the prone position under general anaesthesia. A microscope was used to examine the tissue. Levelling was done using a fluoroscope. For cervical surgeries, a Mayfield clamp was used to fix the head in a flexed position. A midline posterior approach was used with sub-periosteal dissection to expose laminae bilaterally. Facet joints were carefully preserved. Laminectomy was performed at the level of the tumour, ensuring that we had adequate exposure of the cranial and caudal limits of the tumour. After extradural haemostasis, a midline durotomy was performed using a hook and knife. The posterior median sulcus was then identified and gently opened to access the tumour. We did not use coagulation and stayed within the limits of the tumour, performing internal debulking with the help of a Cavitron Ultrasonic Surgical Aspirator (CUSA). After limited debulking, we dissected the tumour from the margins and rolled it inward. Once the dissection was completed up to the normal cord, we completed the haemostasis. We used Surgicel (Fibrillar and other) to achieve proper haemostasis. Somatosensory evoked potential (SSEP) and motor evoked potential (MEP) monitoring was not used. The dura was closed in a watertight fashion using non-absorbable sutures with or without dural graft according to the intraoperative situation to avoid cord strangulation, and the Valsalva manoeuvre was performed to identify any leaks. The wound was then closed in layers. A steroid was prescribed preoperatively to patients with acute neurological deterioration or oedematous signs of the surrounding spinal cord tissue on MRI.

\section{Statistical analysis}

Statistical analysis was performed using SPSS 16.0 for Windows (SPSS Inc., Chicago, IL, USA). The chi-square test was used to evaluate the categorical variables, and the independent samples $t$ test was used for continuous variables. Statistical significance was defined as $p<0.05$.

\section{Results}

As shown in Table 1, there were 12 males (75\%) and 4 females (25\%). The mean age was 50.4 years, ranging from 18 to 70 years. The post-operative follow-up period ranged from 4 to 36 months (mean 15 months). Basic demographic data, clinical presentation, and radiologic exams were retrospectively reviewed for each patient. Patients' neurological status before surgery, immediately after surgery and at last follow-up, was graded using the MMS (Table 2) [4].

The most common presenting symptom was back pain $(n=14,87.5 \%)$, followed by sensory changes $(n=9$, $56.25 \%)$ and then motor weakness $(n=6,37.5 \%)$. Tumour localization was most commonly cervical $(n=8$, $50 \%)$, followed by dorsal $(n=7,43.75 \%)$ and then conus $(n=1,6.25 \%)$. Tumour extension was four or fewer segments in 9 patients $(n=9,56.25 \%)$ and more than four segments in 7 patients $(n=7,43.75 \%)$. Histologically, there were 14 cases of neuroepithelial tumours $(n=14$, $87.5 \%)$ and two cases of non-neuroepithelial tumours $(n=2,12.5 \%)$. One patient was diagnosed with haemangioblastoma $(n=1,6.25 \%)$. One patient was diagnosed with haemangioma $(n=1,6.25 \%)$. Astrocytoma was diagnosed in five patients $(n=5,31.25 \%)$; it was high grade in three patients $(n=3,18.75 \%)$ and low grade in two $(n=2,12.5 \%)$. Ependymoma, always of low grade, was diagnosed in nine patients $(n=9$, $56.25 \%$ ) and was the most common histological origin of IMSCT (Table 1).

\section{Surgical outcome}

In the preoperative evaluation, the median MMS was 3.25. Three patients presented with grade II neurological status, seven patients presented with grade III neurological status, five patients presented with grade IV neurological status, and one patient presented with 


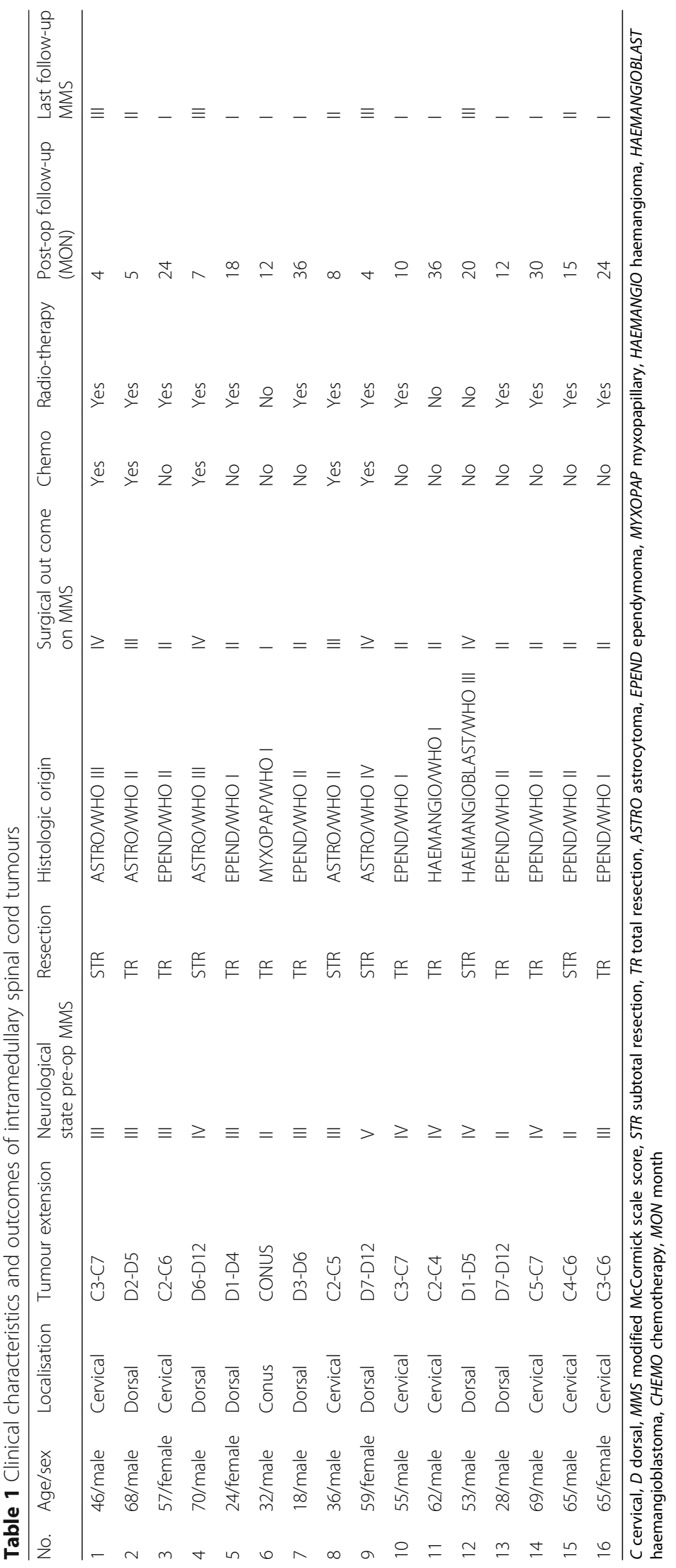


Table 2 Modified McCormick scale

\begin{tabular}{ll}
\hline Grade & Modified McCormick scale \\
\hline II & $\begin{array}{l}\text { Intact neurologically, normal ambulation, minimal dysesthesia } \\
\text { III }\end{array}$ \\
IV & $\begin{array}{l}\text { Moderate deficit, limitation of function, independent with } \\
\text { external aid }\end{array}$ \\
$V$ & $\begin{array}{l}\text { Severe motor or sensory deficit, limited function, dependent } \\
\text { Paraplegia or quadriplegia, even with flickering movement }\end{array}$ \\
\hline
\end{tabular}

grade V neurological status. Post-operatively, we classified surgical outcomes into good=grades I, II, and III and poor = grades IV and V. Before discharge, the patients were evaluated with the MMS as follows: nine patients improved $(n=9,56.25 \%)$, six patients showed no change $(n=6,37.5 \%)$, and one patient worsened $(n=1$, 6.25\%) (Table 1). At the last follow-up, the median MMS was $1.7 ; 14$ patients improved $(n=14,87.5 \%)$, and two patients showed no changes $(n=2,12.5 \%)$ (as shown in Fig. 1 and Table 3).

\section{Tumour resection}

Ten patients underwent total resection (TR), and six patients underwent subtotal resection (STR). Preoperative poor MMS was identified in three patients of the totally resected group $(n=3,30 \%)$ as well as in the subtotal resection group $(n=3,50 \%)(p=0.424)$. Post-operatively, MMS scores improved in all the patients in the TR group $(n=10,100 \%)$ (MMS score 3 or less), while scores improved in only two patients $(n=2$, $33.3 \%)$ in the subtotal resection group $(p=0.008)$. MMS score improvement was clinically and statistically significant in the TR group at last follow-up $(p=0.003)$.

\section{Tumour localisation}

A cervical tumour was detected in eight cases, a dorsal tumour was detected in seven cases, and a conus tumour was detected in one case. A poor preoperative MMS score was detected in three cervical tumours $(n=3$, $37.5 \%)$ and three dorsal tumours $(n=3,42.9 \%)(p=0.710)$. Post-operatively, the score was clinically but not statistically improved in seven cervical cases $(87.5 \%)$ and four dorsal cases $(57.1 \%)(p=0.334)$.

\section{Tumour extension}

Fewer than four segments were involved in 9 cases, and four or more segments were involved in 7 cases. Preoperatively, a good score was detected in 7 cases (77.8\%) of fewer than four segments, while three patients $(42.9 \%)$ with more than 4 involved segments received good scores $(p=0.152)$. Post-operatively, 9 patients (100\%) with fewer than four involved segments improved, while three patients $(42.9 \%)$ with 4 or more involved segments received good scores $(p=0.019)$.

\section{Histological types}

The majority of histopathological variants were ependymoma tumours $(n=9,56.2 \%)$. Astrocytoma was identified pathologically in five cases (31.2\%). Haemangioma and haemangioblastoma were identified in one case each (6.2\%). Good preoperative MMS scores were found in seven patients with ependymoma $(n=7,77.8 \%)$, three patients with astrocytoma $(n=3,60 \%)$, no patients with haemangioma $(n=0)$, and no patients with haemangioblastoma $(n=0)$. Good post-operative MMS scores were found in all nine patients with ependymoma $(n=9100 \%)$, two with astrocytoma $(n=2,40 \%)$,

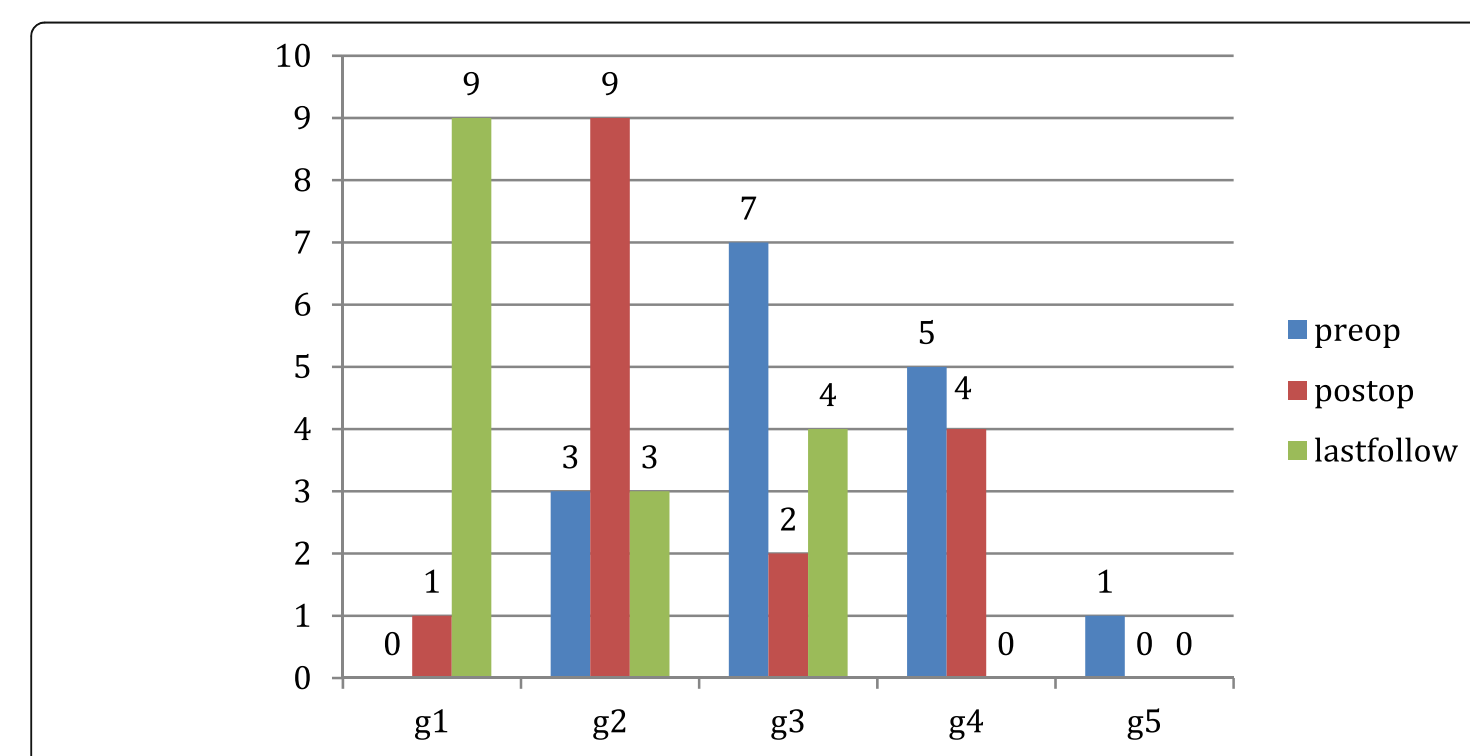

Fig. 1 Preoperative, post-operative, and last follow-up MMS grades 
Table 3 Surgical outcome according to different variables

\begin{tabular}{|c|c|c|c|c|}
\hline & & $\begin{array}{l}\text { Preoperative } \\
\text { good }\end{array}$ & $\begin{array}{l}\text { Post-operative } \\
\text { good }\end{array}$ & $p$ value \\
\hline \multirow[t]{2}{*}{ Resection } & Total & 7 & 10 & 0.008 \\
\hline & Subtotal & 3 & 2 & \\
\hline \multirow[t]{2}{*}{ Localization } & Cervical & 5 & 7 & 0.334 \\
\hline & Dorsal & 4 & 4 & \\
\hline \multirow[t]{2}{*}{ Extension } & $\begin{array}{l}\text { Fewer than } 4 \\
\text { segments }\end{array}$ & 7 & 9 & 0.019 \\
\hline & $\begin{array}{l}\text { More than } 4 \\
\text { segments }\end{array}$ & 3 & 3 & \\
\hline \multirow[t]{4}{*}{ Histology } & Astrocytoma & 3 & 2 & 0.022 \\
\hline & Ependymoma & 7 & 9 & \\
\hline & Haemangioma & 0 & 1 & \\
\hline & Haemangioblastoma & 0 & 0 & \\
\hline
\end{tabular}

one with haemangioma $(n=1,100 \%)$, and none with haemangioblastoma $(\mathrm{n}=0)(p=0.022)$.

\section{Post-operative complications}

Common complications were cerebrospinal fluid leak occurred in two cases in which dural grafts were used, post-operative haematoma in one case, tumour recurrence in two cases at last follow-up, and UTI in one case (illustrative case, Fig. 2).

\section{Discussion}

The management of IMSCTs has progressed during the last few decades. Advances in imaging and surgical techniques have led to many tumours being removed with a high success rate and low morbidity [3]. Because total removal of the tumour may injure the normal spinal cord around the tumour, a conservative surgery followed by irradiation is recommended for IMSCTs [5]. Surgical removal of IMSCTs has become much safer and is associated with good outcomes thanks to high-field MRI and surgical tools, including microscopes with high-definition technology, ultrasonic aspirators and intraoperative monitoring [6]. Complete tumour removal via microsurgical resection is considered the gold standard in the treatment of IMSCTs [7]. We studied patients with IMSCTs who were surgically treated at our hospitals during the last 3 years; our sample of 16 patients is small but comparable to that of most other studies, although a few studies with larger sample sizes have been reported. Our median follow-up was 15 months, which was less than that in other studies.

In our study, the extent of tumour resection was associated with the post-operative neurological outcome, which was statistically and clinically measured. The rate of gross TR was approximately $62.5 \%$ for all tumours, $88.9 \%$ for ependymoma, and $11.1 \%$ for other tumours. Patients with malignant intramedullary tumours treated with gross TR had a significantly lower mortality and improved prognosis compared with patients treated with subtotal resection, biopsy, or non-surgical measures [2]. Advanced microsurgical skills and intraoperative neurophysiological monitoring have enabled more aggressive efforts for TR and near total resection of IMSCTs [8]. Our study emphasises that TR has a good outcome, as reported in a series with complete tumour removal and good post-operative functional outcome [9]. In high-grade tumours and tumours for which total removal is impossible, partial resection or biopsy with radiotherapy and chemotherapy is suggested.
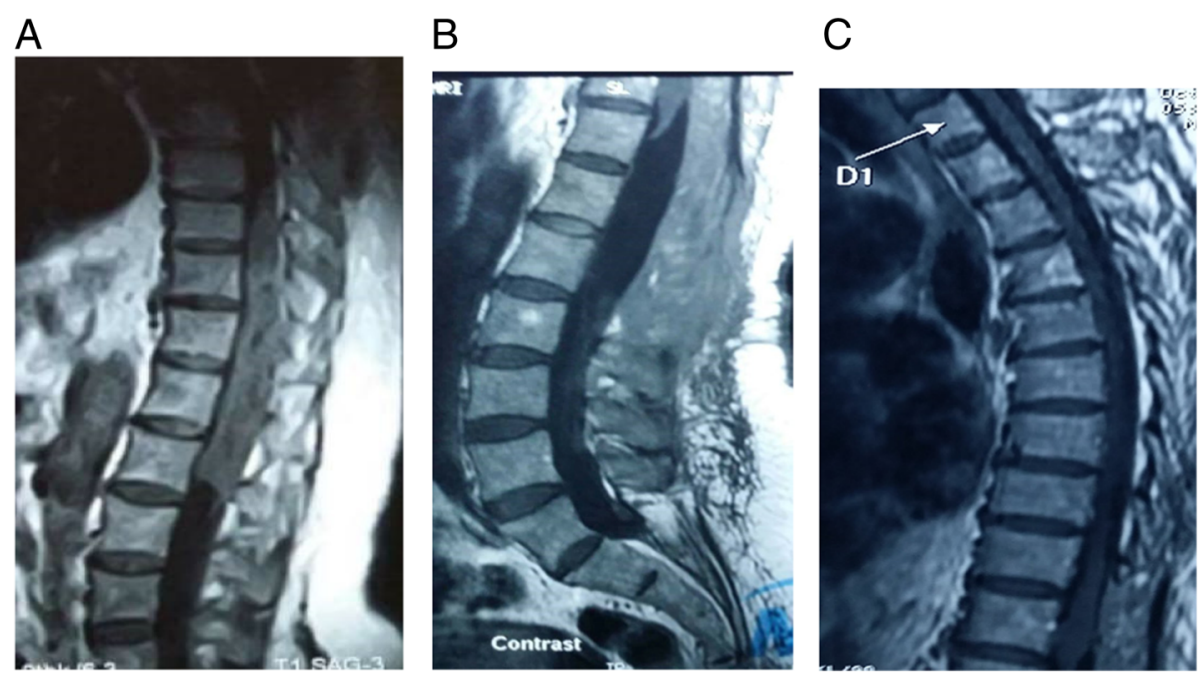

Fig. 2 Male patient, 32 years old, presented with low back pain, bilateral sciatic pain, and paraesthesia with attacks of severe claudication pain and perianal hypoesthesia. Image a MRI-T1W sagittal image showing hyper-intense contrast IMSCT (conus lesion). Images $\mathbf{b}$ and $\mathbf{c}$ Post-op MRIT1W sagittal image showing total resection of myxopapillary ependymoma 
We found the patients' preoperative neurological state to be McCormick grades 1, 2 or 3, meaning that they could walk independently and had a mild neurological condition. These low grades are the strongest predictive factor for a good neurological outcome after surgery, which was clinically but not statistically indicated. These results are supported by findings of previous reports [10] that also recommend early surgical intervention before patients lose the ability to walk [11].

Few studies report the importance of the number of segments involved. Sandalcioglu et al. [12] found no difference in outcome with respect to tumour extension, while Ardeshiri et al. [6] found that tumours extending four or more segments deteriorated significantly after surgery. In our study, we analysed the level of tumour extension and found that good post-operative surgical outcomes were associated with fewer involved segments, while tumour localisation in thoracic lesions was associated with poor surgical outcomes. Thoracic cord tumours have been associated with a poor neurological prognosis [13]. Early surgical interventions are important in cases of thoracic tumours, even if the neurological defect is mild. Because of the prolonged compression in IMSCTs, the amount of blood flow is reduced. The possibility of a poor post-operative prognosis increases when there is a neurological defect. Additionally, the thoracic spinal cord is more susceptible to radiation damage [14], which may be a cause of neurological defects in survivors with malignant tumours.

In this study, we found that high-grade tumours had poor neurological outcomes. This finding may have been because high-grade tumours tend to infiltrate the normal spinal cord, which results in an obscure surgical plane. Additionally, high-grade tumours require pre- or post-operative radiotherapy, which could result in poor functional outcomes [15]. Preoperative radiotherapy may cause radiation-induced myelopathy and/or myelitis and compromise the spinal cord microvasculature, which leads to spinal cord ischaemia [16].

Radiation therapy involving neuro-epithelial tumours may be useful for residual tumours after surgery and for recurrent tumours, but controversy exists regarding this treatment [17]. This modality may also be the primary treatment for inoperable tumours and aggressive lesions such as anaplastic astrocytoma and glioblastoma. One study reported reduced local failure rates when a total radiation dose of $50 \mathrm{~Gy}$ was administered [18]. Modern techniques such as image-guided radiotherapy or stereotactic radiosurgery can ensure the delivery of a therapeutically effective dose to the tumour while sparing the healthy surrounding tissue [19].

Intraoperative neurophysiologic monitoring (IONM), including the somatosensory evoked potential (SSEP) and motor evoked potential (MEP), has been advocated to help maintain patients' neurological function after surgery, which, along with excision of the entire tumour, is the aim in most procedures. Many reports have shown that IMSCT surgery with intraoperative neurophysiologic monitoring (IONM) resulted in a complete IMSCT removal and good neurological performance [20]. In our study, we did not use IONM due to a lack of availability or to technical problems.

\section{Study limitations}

The small number of study participants and the short post-operative follow-up period were important limitations in our study. Another limitation is the lack of IONM, which is considered a significant tool in many studies. Despite these limitations, our study highlights important aspects in the evaluation, management and neurological outcomes of IMSCTs.

\section{Conclusion}

Surgical management of IMSCTs is markedly improving, with less deterioration and a lower complication rate. Total tumour resection with good preoperative clinical condition is considered the most important factor for good neurological outcomes. Tumour localization in the dorsal region with multi-segmental extension is considered a poor prognostic factor for neurological outcome. Advanced pathological grading with poor neural and tumour tissue differentiation carries a high risk of post-operative morbidity and mortality.

\section{Abbreviations \\ ASTRO: Astrocytoma; C: Cervical; CHEMO: Chemotherapy; CUSA: Cavitron Ultrasonic Surgical Aspirator; D: Dorsal; EPEND: Ependymoma; HAEMANGIO: Haemangioma; HAEMANGIOBLAST: Haemangioblastoma; IMSCT: Intramedullary spinal cord tumours; IONM: Intraoperative neurophysiologic monitoring; MEP: Motor evoked potential; MMS: Modified McCormick Scale; MON: Month; MRI: Magnetic resonance images; MYXOPAP: Myxopapillary; SSEP: Somatosensory evoked potential; STR: Subtotal resection; TR: Total resection; WHO: World Health Organization}

\section{Acknowledgements}

The authors acknowledge all member staff of neurosurgery departments in Al-Azhar University Hospitals and Mohammad Dossary hospital, for their support and help during this work.

\section{Funding \\ The authors received no financial support for the research, authorship, and/ or publication of this article.}

\section{Availability of data and materials}

The datasets used and/or analysed during the current study are available from the corresponding author on reasonable request.

\section{Authors' contributions}

All the following authors contributed their work in this study among themselves, and each one of them has full responsibilities. All authors read and approved the final manuscript.

\section{Ethics approval and consent to participate}

The medical ethics committee of Faculty of Medicine for Girls, Al-Azhar University, approved this study. The reference Number of the committee is not available and the date of approval was at June 2014. Before and during this 
study the informed consent was obtained from all study participants after brief discussion and explanation with them.

\section{Consent for publication}

All authors accept that only EJNS has all authority for publications and subsequent responsibilities. Also the informed consent for publication was obtained from all study participants after discussion and explanation with them.

\section{Competing interests}

The authors declare that they have no competing interests.

\section{Publisher's Note}

Springer Nature remains neutral with regard to jurisdictional claims in published maps and institutional affiliations.

Received: 11 October 2018 Accepted: 6 January 2019

Published online: 21 January 2019

\section{References}

1. Mitha AP, Turner JD, Spetzler RF. Surgical approaches to intramedullary cavernous malformations of the spinal cord. Neurosurgery. 2011;68(2 Suppl Operative):317-24 discussion 324

2. Wong AP, Dahdaleh NS, Fessler RG, Melkonian SC, Lin Y, Smith ZA, et al. Risk factors and long-term survival in adult patients with primary malignant spinal cord astrocytomas. J Neuro-Oncol. 2013;115:493-503.

3. Manzano G, Green BA, Vanni S, Levi AD. Contemporary management of adult intramedullary spinal tumors - pathology and neurological outcomes related to surgical resection. Spinal Cord. 2008:46(8):540-6.

4. McCormick PC, Torres R, Post KD, Stein BM. Intramedullary ependymoma of the spinal cord. J Neurosurg. 1990;72:523-32.

5. Schwade JG, Wara WM, Sheline GE, Sorgen S, Wilson CB. Management of primary spinal cord tumor. Int J Radiat Oncol Biol Phys. 1978:4:389-93.

6. Ardeshiri A, Chen B, Hütter BO, Oezkan N, Wanke I, Sure U, et al. Intramedullary spinal cord astrocytomas: the influence of localization and tumor extension on resectability and functional outcome. Acta Neurochir. 2013;155:1203-7.

7. Brotchi J, Bruneau M, Lefranc F, Baleriaux D. Surgery of intraspinal cord tumors. Clin Neurosurg. 2006;53:209-16.

8. Kothbauer KF. Intraoperative neurophysiologic monitoring for intramedullary spinal-cord tumor surgery. Neurophysiol Clin. 2007;37:407-14.

9. Minehan KJ, Shaw EG, Scheithauer BW, Davis DL, Onofrio BM. Spinal cord astrocytoma: pathological and treatment considerations. J Neurosurg. 1995; 83:590-5.

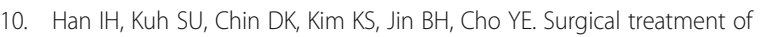
primary spinal tumors in the conus medullaris. J Korean Neurosurg Soc. 2008;44:72-7.

11. Nakamura M, Ishii K, Watanabe K, Tsuji T, Takaishi H, Matsumoto M, et al Surgical treatment of intramedullary spinal cord tumors: prognosis and complications. Spinal Cord. 2008;46:282-6.

12. Sandalcioglu IE, Gasser T, Asgari S, Lazorisak A, Engelhorn T, Egelhof T, Stolke D, Wiedemayer H. Functional outcome after surgical treatment of intramedullary spinal cord tumors: experience with 78 patients. Spinal Cord. 2005;43(1):34-41.

13. Ardeshiri A, Chen B, Hütter BO, Oezkan N, Wanke I, Sure U, Sandalcioglu IE. Intramedullary spinal cord astrocytomas: the influence of localization and tumor extension on resectability and functional outcome. Acta Neurochir (Wien). 2013;155(7):1203-7. https://doi.org/10.1007/s00701-013-1762-5 Epub 2013 May 23.

14. Lambert PM. Radiation myelopathy of the thoracic spinal cord in long term survivors treated with radical radiotherapy using conventional fractionation. Cancer. 1978;41:1751-60.

15. Woodworth GF, Chaichana KL, McGirt MJ, Sciubba DM, Jallo Gl, Gokaslan Z, et al. Predictors of ambulatory function after surgical resection of intramedullary spinal cord tumors. Neurosurgery. 2007;61(1):99-105.

16. Marcus RB Jr, Million RR. The incidence of myelitis after irradiation of the cervical spinal cord. Int J Radiat Oncol Biol Phys. 1990;19:3-8.

17. Chang UK, Choe WJ, Chung SK. Surgical outcome and prognostic factors of spinal intramedullary ependymomas in adults. J Neuro-Oncol. 2002;57(2):133-9.
18. Jyothirmayi R, Madhavan J, Nair MK, Rajan B. Conservative surgery and radiotherapy in the treatment of spinal cord astrocytoma. J Neuro-Oncol. 1997;33(3):205-11.

19. Wowra B, Muacevic A, Zausinger S, Tonn JC. Radiosurgery for spinal malignant tumors. Dtsch Arztebl Int. 2009;106(7):106-12.

20. Sala F, Palandri G, Basso E, Lanteri P, Deletis V, Faccioli F, et al. Motor evoked potential monitoring improves outcome after surgery for intramedullary spinal cord tumors: a historical control study. Neurosurgery. 2006;58:1129-43.

\section{Submit your manuscript to a SpringerOpen ${ }^{\circ}$ journal and benefit from:}

- Convenient online submission

- Rigorous peer review

- Open access: articles freely available online

- High visibility within the field

- Retaining the copyright to your article

Submit your next manuscript at $\boldsymbol{\nabla}$ springeropen.com 